\title{
Chapter 9 \\ Living Green: New Chapter of Consumption and Social Governance
}

\begin{abstract}
We all hope that everyone can protect the earth and live a better life. As consumers are the last link in the carbon emission chain, hundreds of millions of consumers need to play their part in achieving the carbon peak by 2030 and carbon neutrality by 2060 . Everyone can contribute by changing the way they live and consume.

In the meantime, consumers may face increased costs and inconvenience brought by green consumption. However, we believe this is a worthwhile since changes and sacrifices of several generations will bring a better life for future generations.

In this chapter, we emphasize the need to change our lifestyle and social governance as well as the reinforcing interaction between the two. Enterprises should take measures to effectively lower cost and improve economies of scale, quality and experience of green consumption. Governments should improve green standards, introduce subsidies and formulate policies and regulations to facilitate consumers' shift to green consumption and lifestyle changes.

Let us work together to build healthies lifestyles with clear water and green mountains, and to build and share a beautiful era of carbon neutrality.
\end{abstract}

\subsection{Living Green Needs Efforts of All Stakeholders}

\subsubsection{Low-Carbon Lifestyle is of Great Significance as Households Are Responsible for $40 \%$ of Total Carbon Emissions}

Households generate carbon emissions both directly and indirectly. Energy consumption contributes directly to the carbon footprint of households, while indirect carbon emissions are generated by consumption and services purchased in daily life. According to the definition of 'carbon footprint', indirect carbon emissions also include emissions generated in producing consumer goods. We estimate that carbon 


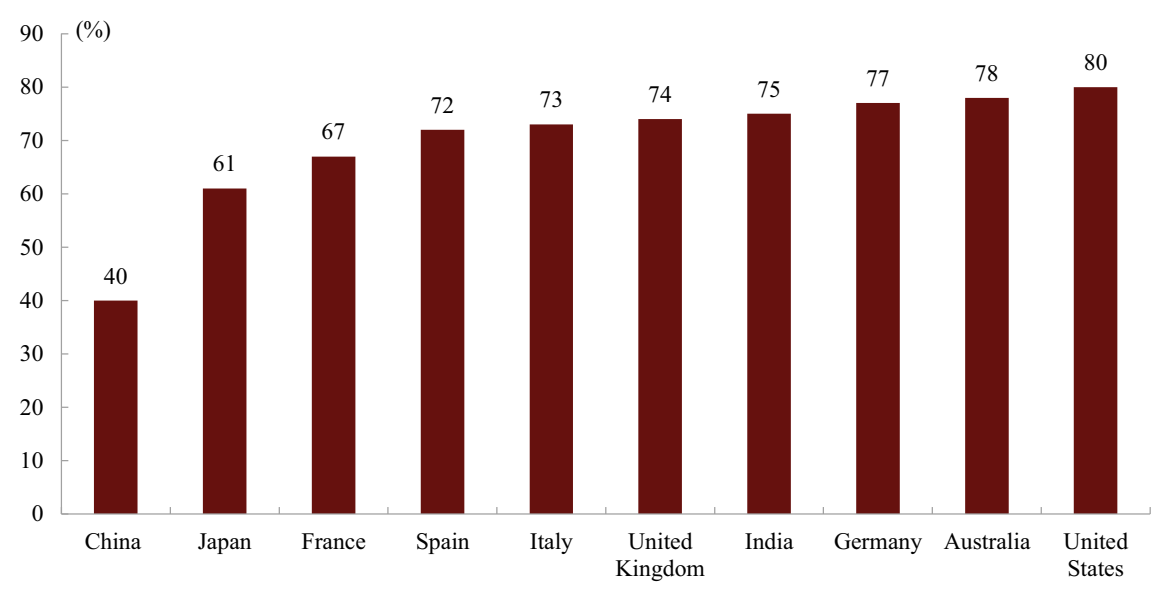

Fig. 9.1 Proportions of household carbon footprints by country. Note Research data is compiled based on 2017 data. Source Mapping the Carbon Footprint of EU regions, Diana Ivanova et al. Environ. Res. Lett. 12 (2017) 054013, How to Reduce Household Carbon Emissions: A Review of Experience and Policy Design Consideration, Xiaoling Zhang et al. Energy Policy 102 (2017) 116-124, CICC Research

emissions from households account for approximately $40 \%$ of China's total emissions, ${ }^{1}$ compared to $60 \%-80 \%$ in developed economies ${ }^{2}$ (Fig. 9.1). Households may account for a higher proportion of total carbon emissions as their living standards improve. Therefore, living a green lifestyle is crucial for carbon neutrality.

\subsubsection{Social Governance Requires Efforts from Households, Companies, and Government}

How to lower the proportion of household carbon footprint in total carbon emissions? A low-carbon lifestyle may play an important role in achieving carbon neutrality. As the economy continues to grow, the proportion of household carbon footprint is increasing. Living a low-carbon lifestyle has become increasingly important, and needs the engagement of all stakeholders: Households should turn to low-carbon consumption, businesses should step up innovations and efforts to reduce supply-side carbon emissions, and governments should introduce favorable policies. Therefore, breakthroughs relating to household lifestyles, business models, and government policies are necessary to achieve green consumption (Fig. 9.2).

What can households do to help achieve carbon peak? Households can take measures to reduce demand-side carbon emissions, such as adoption of green

\footnotetext{
${ }^{1}$ How to Reduce Household Carbon Emissions: A Review of Experience and Policy Design Consideration, Xiaoling Zhang et al. Energy Policy 102 (2017) 116-124.

${ }^{2}$ Mapping the Carbon Footprint of EU Regions, Ivanova et al. Environ. Res. Lett. 12 (2017) 054,013.
} 


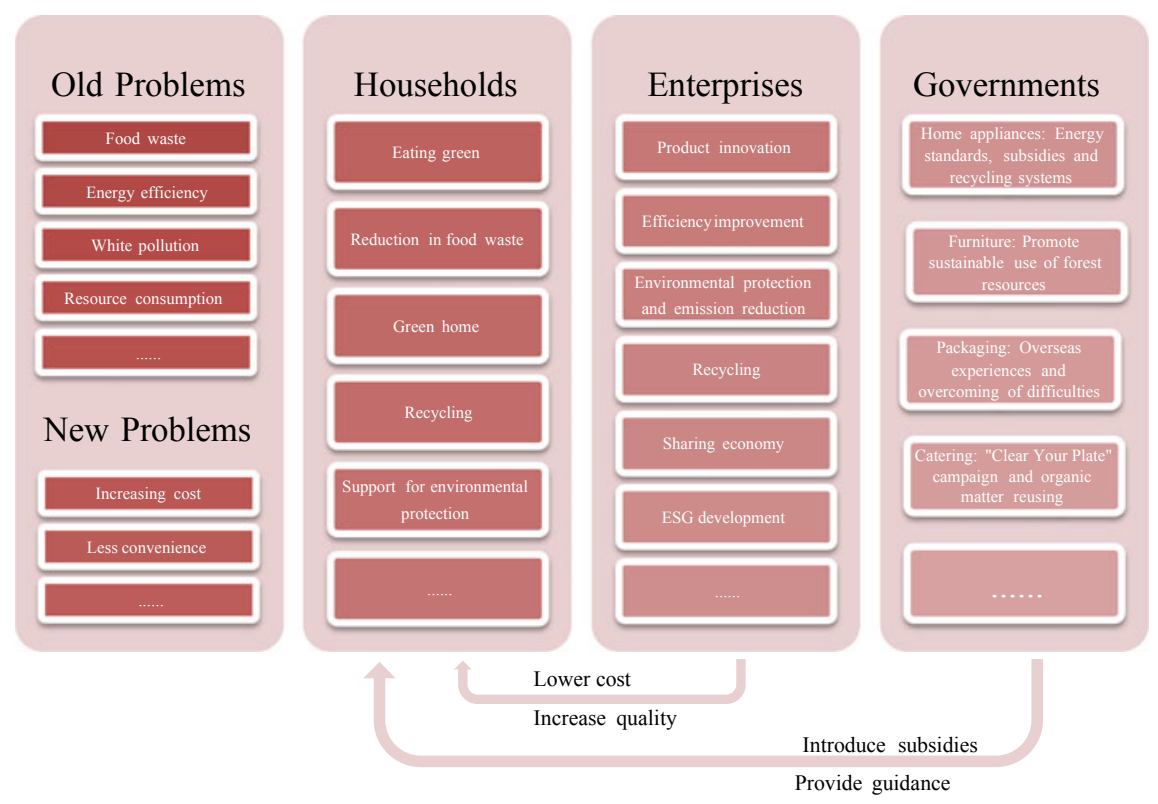

Fig. 9.2 Roadmap of green lifestyle. Source CICC Research

lifestyles, cultivation of green consumption habits, improvement of consumer behaviors, as well as practicing a low-carbon diet, waste reduction, energy conservation and environmental protection.

However, households may face new problems in this process, i.e., rising costs and inconvenience. The engagement of enterprises and governments can help address these issues and enable households to play their roles in the achievement of carbon neutrality.

What can consumer goods companies do to help achieve carbon peak? Enterprises can take multiple measures to reduce supply-side carbon emissions, such as product innovation, efficiency improvement, energy consumption reduction, environmental protection, recycling, reusing, sharing economy, and ESG development. In addition, enterprises can achieve economies of scale in green consumer products to lower household expenses on their products.

What can governments do to help achieve carbon peak? Governments should introduce favorable policies to encourage enterprises to take more ambitious measures. These policies include energy efficiency system and recycling of home appliances, subsidies for energy-saving products, sustainable use of forest resources, comprehensive management of packaging, "Clear Your Plate" campaign and reusing of organic products. Implementation and improvement of these policies may also help lower the incremental cost of households. 


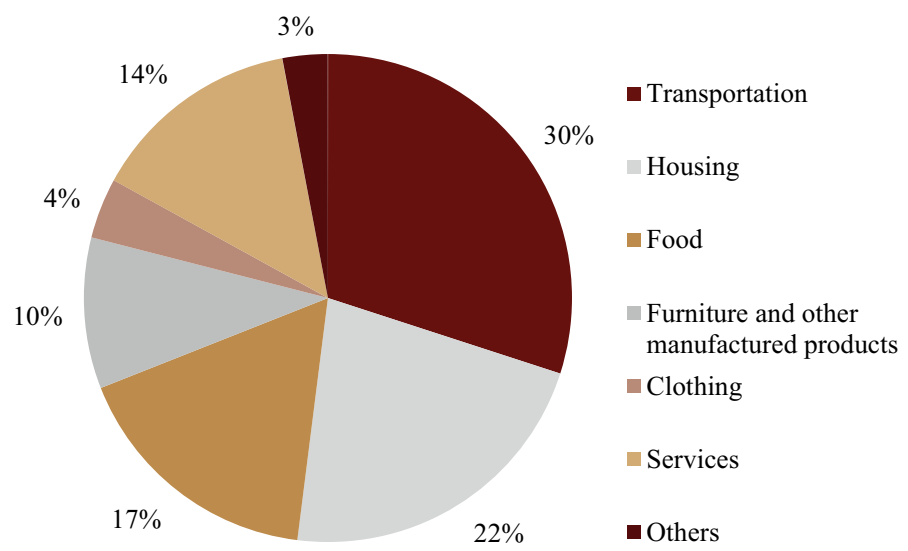

Fig. 9.3 Carbon emission breakdown of European households in 2017. Source Mapping the Carbon Footprint of EU Regions, Diana Ivanova et al. Environ. Res. Lett. 12 (2017) 054,013, CICC Research

\subsection{Green Lifestyle: What Can Households Do to Help Achieve Carbon Peak?}

Studies have shown that transportation, food, housing, furniture and other manufactured products account for 30\%, 17\%, 22\%, 10\% and 4\% of the average carbon footprint of European households in 2017 (Fig. 9.3) (see Footnote 2). This section mainly discusses green diet and green home that jointly account for approximately $39 \%$ of the average household carbon footprint.

\subsubsection{Eating Green}

Vegetarian diets produce much lower carbon emissions than meat, mainly due to low utilization of feed and methane gas emissions from animals. Carbon emissions generated by producing beef and mutton are four times as high as those from chicken and pork ${ }^{3}$ (Fig. 9.4). On the average US diet, meat products account for $56.6 \%$ of total carbon emissions in 2018, being the largest component of dietary carbon emissions ${ }^{4}$ (Fig. 9.5). As for dietary consumption is mainly rice, meat products account for approximately $36.6 \%$ of all carbon emissions from food in China in 2016 (Fig. 9.6).

\footnotetext{
${ }^{3}$ A Comparative Study on Carbon Footprints Between Plant and Animal-based Foods in China, Xu et al. Journal of Cleaner Production 112 (2016) 2581-2592.

${ }^{4}$ Center for Sustainable Systems, University of Michigan, 2020.
} 


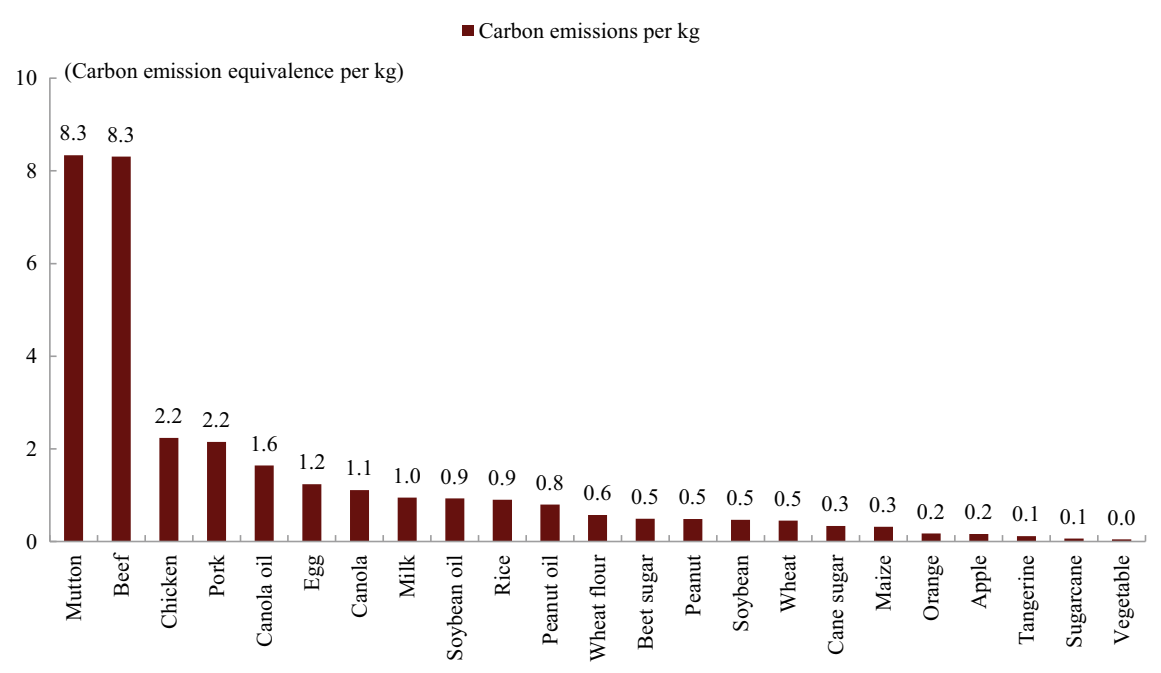

Fig. 9.4 Estimated per kg carbon emission from food production and consumption in China. Source A Comparative Study on Carbon Footprints Between Plant and Animal-based Foods in China, Xu et al. Journal of Cleaner Production 112 (2016) 2581-2592, CICC Research

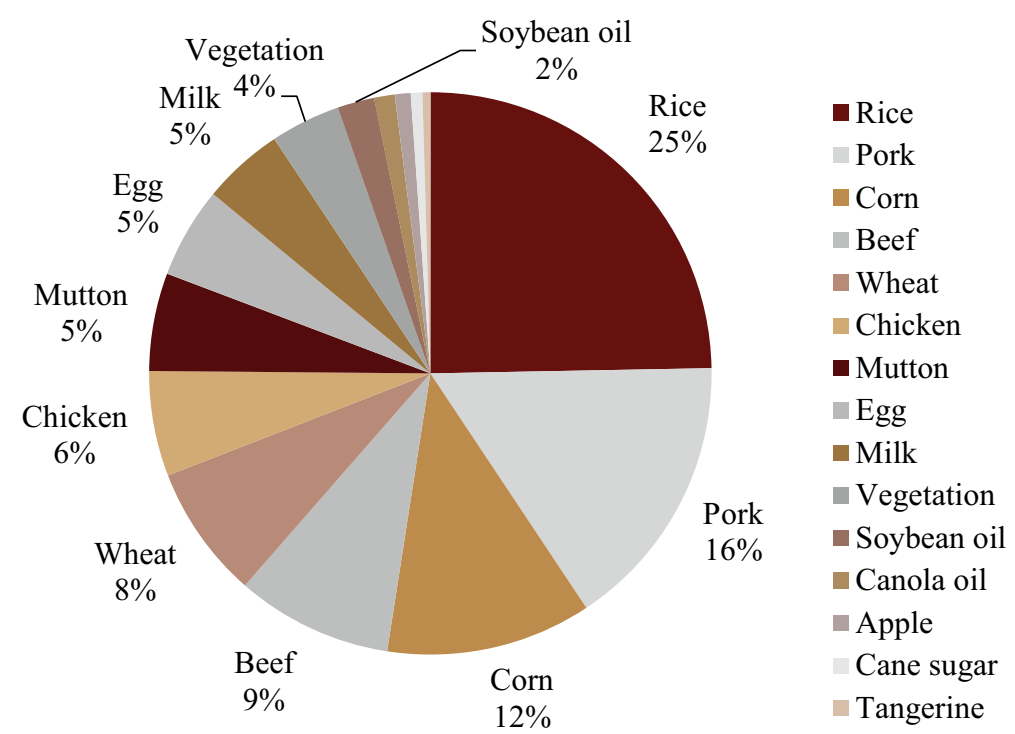

Fig. 9.5 Carbon footprint breakdown by type of food in 2016 in China. Note Data on carbon footprint of aquatic products is not available. Source Food and Agriculture Organization, A Comparative Study on Carbon Footprints Between Plant and Animal-based Foods in China, Xu et al. Journal of Cleaner Production 112 (2016) 2581-2592, CICC Research 


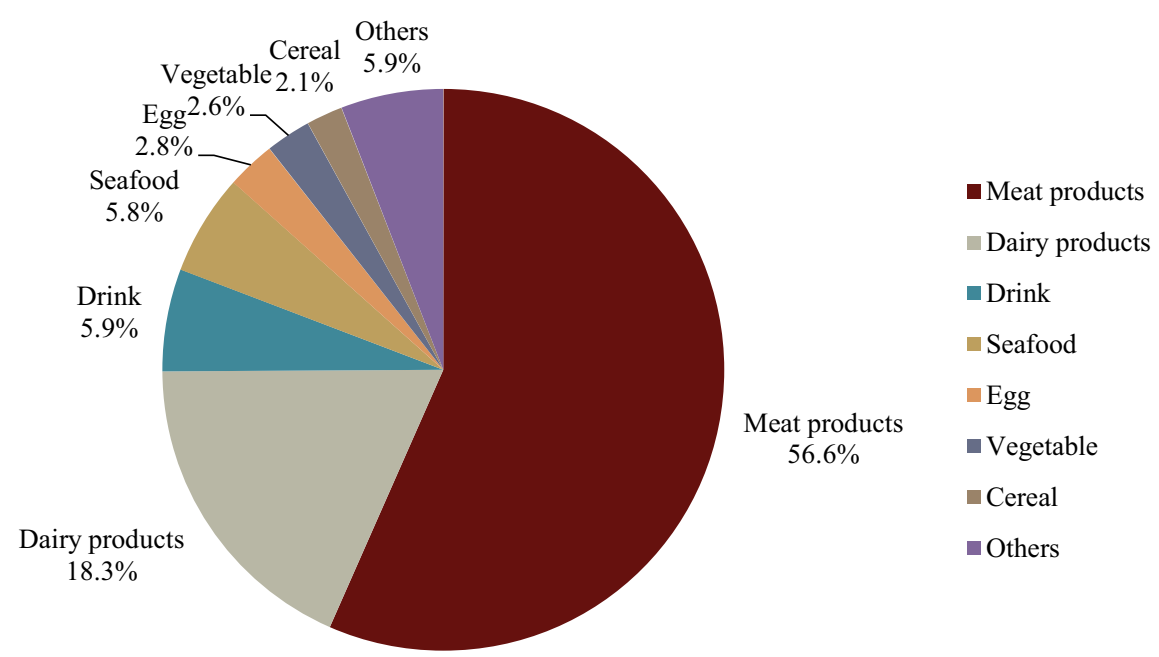

Fig. 9.6 Carbon footprint breakdown by type of food in 2018 in the U.S. Source Center for Sustainable Systems, University of Michigan, CICC Research

For adults, carbon footprints of vegan diets and ovo-lacto vegetarian diets are $59 \%$ and $65 \%$ of that of omnivorous diets, ${ }^{5}$ and could provide all the nutrients that a human being needs. ${ }^{6}$ According to our calculations, improving eating habits alone can reduce carbon emissions by $66.21 \mathrm{mn}$ tonnes by 2030 . Therefore, green diet can play an important role in achieving carbon peak by 2030 and carbon neutrality by 2060.

The improvement of the dietary structure depends on government advocacy and guidance, as well as on innovations in food processing. Using vegetarian food to emulate meat can minimize changes in tastes from the adjusted dietary structure, which will help the transformation of dietary structure. Among these innovations, plant-based meat production technology has advanced. Founded in 2009 (US), Beyond Meat has become the world's largest producer of plant-based meats. The company's plant-based products are designed to have the same taste as animal-based meat. Beyond Meat offers Beyond Burger, Beyond Beef, Beyond Fried Chicken, and Beyond Sausage, covering various products. According to $3 \mathrm{Q} 20$ earnings announcement, Beyond Meat's market share of the US retail channel increased $6.14 \mathrm{ppt}$ YoY in 3 Q20.

Eating more vegetables, moderate amount of poultry and less red meat, as well as switching to an ovo-lacto vegetarian diet may reduce carbon emissions and could be good for health. Compared to veganism, ovo-lacto vegetarianism may be more easily accepted since it provides nutrition within a more flexible dietary framework.

\footnotetext{
${ }^{5}$ Environmental Impact of Omnivorous, Ovo-lacto-vegetarian, and Vegan diet, Alice Rosi et al. Scientific Reports, 7,6015(2017).

${ }^{6}$ Nutrient Intake of Endurance Runners with Ovo-lacto-vegetarian Diet and Regular Western Diet, M. Eisinger et al., 1994.
} 
Extensive research shows an ovo-lacto vegetarian diet has potential health benefits. According to The Long-term Health of Vegetarians and Vegans, the prevalence of overweight and obesity is lower among ovo-lacto vegetarians and vegans. In addition, ovo-lacto vegetarians and vegans have a lower risk of ischemic heart disease (IHD), and longer life expectancy compared with non-vegetarians from a similar background. Studies also show that compared with eaters of other meats, red meat eaters have a much higher risk of a range of diseases. ${ }^{7}$ The World Health Organization (WHO) announced that the consumption of red meat is probably carcinogenic to human beings (Group 2A). Therefore, we suggest eating less red meat, moderate poultry meat, and more vegetables, and considering adopting an ovo-lacto vegetarian diet.

\subsubsection{Reduction in Food Waste}

Food waste at the consumer level is a massive problem, especially at banquets and get-togethers. As consumer spending rises, food waste in China is concentrated at the consumer level. According to the 2018 China Urban Catering Food Waste Report released by the World Wide Fund for Nature (WWF) and the Institute of Geographic Sciences and Natural Resources Research of the Chinese Academy of Sciences, food waste in China's restaurant industry is $93 \mathrm{~g} /$ person/meal, implying a waste rate of $11.7 \%$. Food waste in urban restaurants was about $17-18 \mathrm{mn}$ tonnes in China in 2015. The Chinese Academy of Social Sciences also points out that China wastes 40$50 \mathrm{mn}$ tonnes of grain every year, equivalent to $6.0 \%-7.5 \%$ of the country's annual grain production.

Food waste is more severe for special events such as friends' get-togethers, weddings, birthdays, and business banquets. According to the 2018 China Urban Catering Food Waste Report, the average food waste is $107 \mathrm{~g} /$ person/meal and $102 \mathrm{~g} /$ person/meal at friends' get-togethers and business banquets, compared to $95 \mathrm{~g} /$ person/meal for family gatherings and $67 \mathrm{~g} /$ person $/$ meal for a typical dinner. Food waste is positively correlated to restaurant size. Large restaurants have the largest food waste of $132 \mathrm{~g} / \mathrm{person} / \mathrm{meal}$, compared to an industry average of $93 \mathrm{~g} / \mathrm{person} / \mathrm{meal}$, and $69 \mathrm{~g} /$ person/meal for small restaurants and $38 \mathrm{~g} /$ person/meal for fast-food restaurants.

Reducing food waste in restaurants can lower carbon emissions from food production and reduce greenhouse gas emissions generated by waste going to landfills. In addition, households should purchase consumer goods, such as household supplies, grocery, and clothing, according to actual needs. These moves can help protect natural resources and achieve carbon peak.

\footnotetext{
${ }^{7}$ The Long-term Health of Vegetarians and Vegans. Paul et al. Proc Nutr Soc. 2016 Aug;75(3):28793.
} 


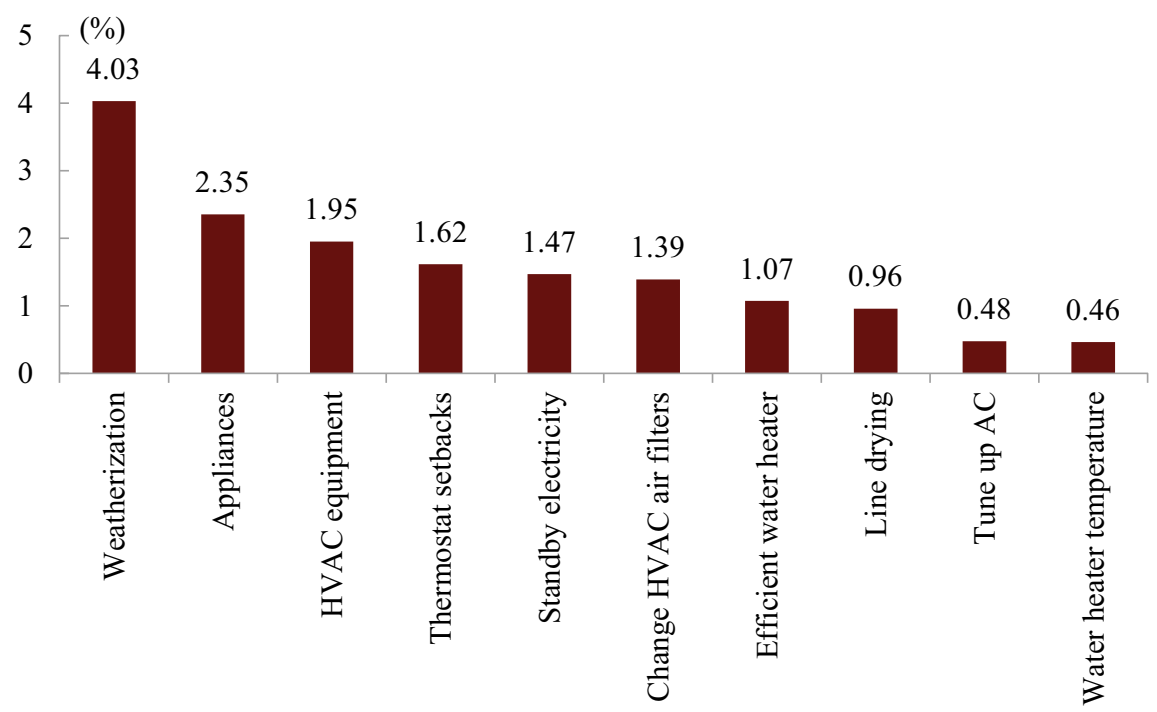

Fig. 9.7 Green home-estimated carbon emission reduction resulting from adoption of certain habits. Source Household Actions Can Provide a Behavioral Wedge to Rapidly Reduce US Carbon Emissions. Thomas Dietz et al. PNAS.0908738106, CICC Research

\subsubsection{Green Home}

Adopting certain habits can help reduce carbon emissions. Although households account for more than $20 \%$ of household carbon footprint, there is no simple solution for reducing carbon emissions of home life. Reducing such carbon emissions depends on technological advancements and energy mix improvements, and more importantly, some daily habits. According to the research from Michigan State University, the adoption of a green lifestyle can reduce carbon emissions of home life by more than $15 \%{ }^{8}$ (Fig. 9.7). Good lifestyles include energy-saving renovation of houses, renovation and maintenance of home appliances, drying clothes under the sun instead of using laundry dryer, and lower temperature of hot water. In addition, waste sorting is also an important part of green home habits.

\subsubsection{Support for Environmental Protection}

As environmental awareness increases, people's consumption patterns will play a bigger role in helping China achieve carbon neutrality.

\footnotetext{
${ }^{8}$ Household Actions Can Provide a Behavioral Wedge to Rapidly Reduce US Carbon Emissions. Thomas Dietz et al. PNAS.0908738106.
} 
Reducing food delivery packaging is an important measure to protect the environment. As the food delivery packaging market is rapidly expanding, left over food packaging has become an important issue and needs to be solved urgently. Consumers can play their roles in reducing unnecessary packaging. Specific measures include reuse of packaging, reduced use of disposable products, and wide use of durable products. The food delivery market is booming due to the popularization of mobile internet. According to iResearch, China's food delivery market increased 39.3\% YoY to Rmb653.6bn in 2019, implying a CAGR of 90\% over 2015-2019. We estimate that, in China, the number of disposable food boxes used in food delivery of restaurants might exceed 30bn in 2019, and the number of packaging bags may exceed $15 \mathrm{bn}$.

Plastics are the main materials for food delivery packaging at current stage. According to Meituan Waimai, the proportion of plastic materials in food delivery packaging boxes and bags exceeds $80 \%$ in 2020. Polypropylene and polyethylene are the most widely used plastic materials. The treatment and recycling markets of food delivery packaging waste remain underdeveloped, and plastics generate a large volume of carbon emissions during landfills or incineration. Constraints in technology, performance and cost prevent degradable packaging from being reused widely.

In addition, there are many things we can do to reduce carbon emissions, such as buying e-books and using paper cups less frequently. As environmental awareness increases, we can protect our future by supporting environmental protection.

\subsection{Green Business Model: What Can Consumer Goods Companies Do to Help Achieve Carbon Peak?}

In the process of reaching carbon peak, enterprises can play an active role in product innovation, efficiency improvement, energy consumption reduction, environmental protection, emission reduction, recycling, economic sharing, and ESG development. These measurements can effectively increase economies of scale, lower cost, and improve the quality and experience of green consumption.

\subsubsection{Product Innovation}

Product innovation can lead to slower growth in household energy consumption. Chinese households consume large volumes of electricity and natural gas, along with a small amount of bulk coal to meet the needs of home appliance operation, cooking, and heating. In 2019, Chinese households consumed 1025bn kWh of electricity, implying 705mn tonnes of carbon dioxide emissions (China's clean energy accounted 
for $31 \%$ of total electricity generation in 2019$) ; 114 \mathrm{bn} \mathrm{m}^{3}$ of natural gas, implying $246 \mathrm{mn}$ tonnes of carbon dioxide emissions; and 60mn tonnes of bulk coal (mainly for heating), implying $114 \mathrm{mn}$ tonnes of carbon dioxide emissions.

Electricity demand by residential users is relatively inelastic. To fundamentally solve the carbon emission problem of household electricity consumption, use of renewable energies such as wind, solar, and hydropower needs to increase substantially, while the use of coal-fired thermal power generation should be reduced. Improving energy efficiency standards of home appliances may help reduce the usage of household electricity. Newly produced home appliances, especially air conditioners and central air conditioners, are more energy efficient. Moreover, the older the home appliance is, the lower its average energy efficiency. Trade-in programs should be introduced to substitute home appliances with poor energy efficiency.

Many new technologies can facilitate the improvement of home appliances' energy efficiency. Inverter technology can improve energy efficiency of air conditioners, refrigerators, and washing machines. Solar water heaters and condensing gas water heaters can alleviate the burden on power grid. LED lights could replace the traditional light bulbs.

\subsubsection{Efficiency Improvement and Energy Consumption Reduction}

Material loss in the process of production is another important factor affecting carbon emissions. The furniture industry is using flexible production and other intelligent manufacturing technologies to continuously improve the utilization rate of timber. In this section, we use the furniture industry as an example to illustrate the potential of the industry's efficiency improvement and energy consumption reduction.

China is the world's second largest consumer of timber, and its timber consumption has continued to increase in recent years (Fig. 9.8). Reducing timber consumption and improving its utilization can play an important role in helping achieve carbon neutrality. The amount of plantation, especially in the form of tree, is crucial for carbon neutrality. One tree can absorb more than $21.8 \mathrm{~kg}$ of carbon dioxide per year (Fig. 9.9). According to data from the China National Forest Products Industry Association and Qianzhan Intelligence, China's timber consumption has increased 173\% in the past decade and it has become the world's second largest consumer and largest importer of timber. The proportion of home furnishings in total timber consumption continues to increase. Wood-based panels account for the highest proportion, at $32.99 \%$, and solid wood furniture products account for about $3 \%$.

As the major consumer of timber, furniture and home decoration industries continuously improve the utilization rate of wooden products through intelligent manufacturing and flexible production. Currently, the timber utilization rate at some leading manufacturers of custom-made furniture exceeds $85 \%$. This utilization rate can effectively lower timber consumption and help achieve carbon neutrality. 


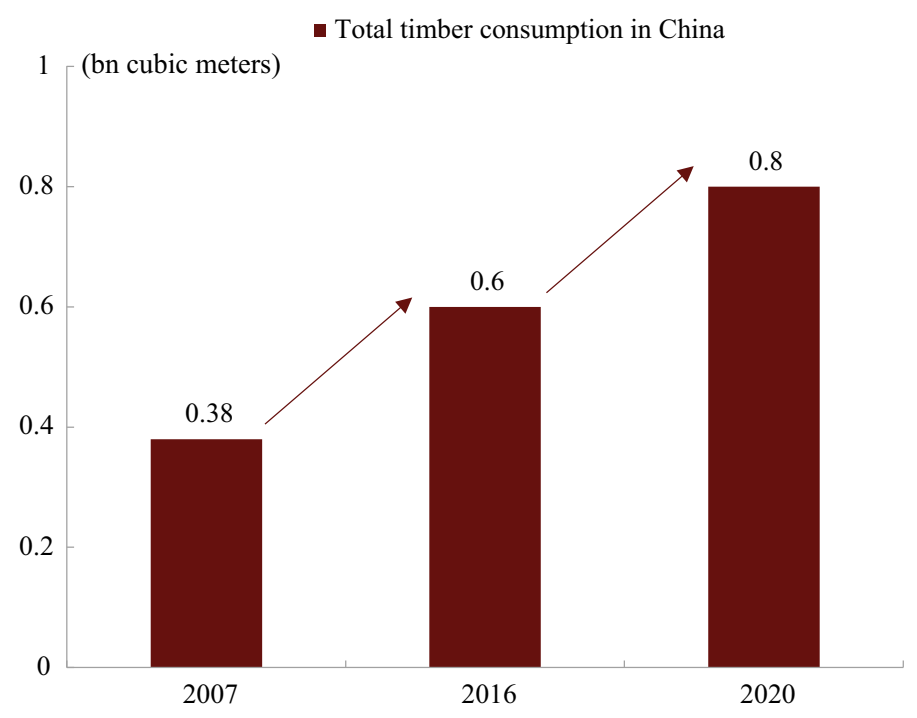

Fig. 9.8 China's timber consumption continues to rise. Source China National Forest Products Industry Association, chinatimber.org, CICC Research

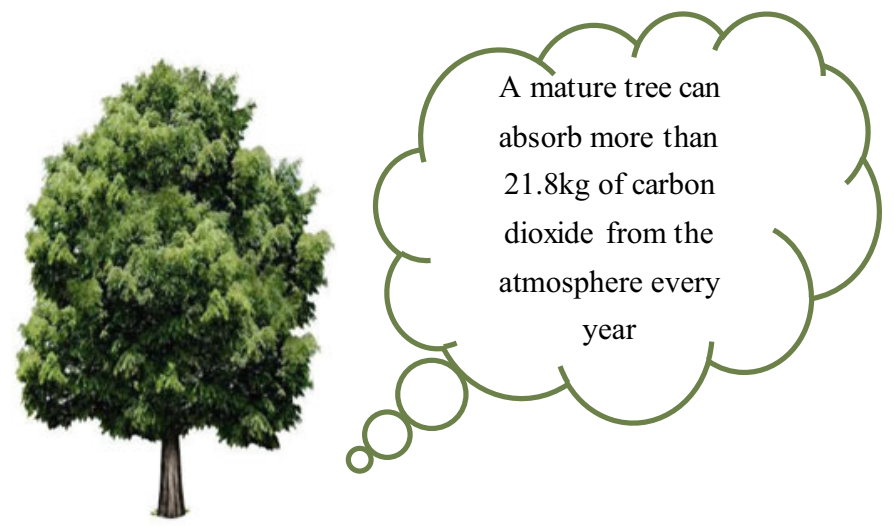

Fig. 9.9 One tree can absorb more than $21.8 \mathrm{~kg}$ of carbon dioxide per year. Source Arbor Day Foundation, CICC Research

Intelligent manufacturing technologies such as advanced flexible production can fully meet the needs of furniture customization. Through the organic combination of microelectronics, computer and system engineering technologies, flexible production technology can effectively cope with the contradiction between high automation and high flexibility in mechanical manufacturing. The technology uses big data and software to automatically combine, calculate, and arrange cabinets of different sizes 
to design the most efficient sawing process. This can help reduce material losses, improve timber utilization rate, and lower timber consumption. China's leading manufacturers of custom-made furniture such as Oppein and Suofeiya continue to increase their timber utilization rate using flexible production technologies.

\subsubsection{Environmental Protection and Emission Reduction}

Environmental pollution resulting from the production process is one of the major obstacles to achieving carbon neutrality. We will use the personal care and textile \& apparel industries as examples to analyze the relation between pollution emission and carbon neutrality and corresponding solutions.

\subsubsection{Manufacturers of Laundry Detergent Have Stepped up Efforts to Reduce Carbon Emissions}

Reduction of carbon emissions in the process of producing laundry detergent plays an important role in achieving carbon neutrality. China's laundry detergent consumption is huge. In 2019, China's laundry detergent market size reached Rmb27.2bn. Assuming an average price of Rmb7.8/500g, China consumed 1.744mn tonnes of laundry detergents in 2019. The penetration rate of laundry detergent in 2019 was about $44 \%$ in China, which was much lower than Japan's 79.5\% and US's 91.4\%. We expect China's laundry detergent market to grow at a rapid CAGR of $13.6 \%$ in the next 5 years, reaching a total of Rmb51.5bn in 2024, which implies a sales volume of $3.30 \mathrm{mn}$ tonnes.

According to Carbonstop, producing one tonne of laundry detergent can generate about 0.67 tonnes of carbon dioxide. We estimate that China's laundry detergent production generated $1.17 \mathrm{mn}$ tonnes of carbon emissions in 2019, then this figure might reach $2.21 \mathrm{mn}$ tonnes in 2024. As consumption of laundry detergent continues to grow, adopting greener formulas and reducing carbon emissions in the production process can play an important role in achieving carbon neutrality in China.

In the context of rising environmental awareness among global enterprises and consumers, the global giants of personal care products have continuously introduced eco-friendly laundry detergents in recent years. Compared with traditional petroleum-derived laundry detergents, eco-friendly laundry detergents are mainly made from all-natural ingredients, which can reduce the carbon footprint during both production and use.

Tide Purclean: As a world-renowned laundry detergent brand, Tide launched Purclean, a 75\% plant-based detergent. Purclean greatly reduces uses of petroleumderived ingredients without compromising on its cleaning performance.

Seventh Generation's Free \& Clear: Seventh Generation is one of the most popular eco-friendly brands in the world. It is a certified partner of Rainforest Alliance and 
Forest Stewardship Council, and $97 \%$ of its Free \& Clear laundry detergent is made from biology-based and plant-based ingredients.

Looking ahead, we firmly believe concentrated laundry detergent will help reduce energy consumption, and lower carbon emissions. According to the Report on Life Cycle Assessment of China's Concentrated Laundry Detergent released by China Cleaning Industry Association, if all Chinese consumers switch to concentrated laundry detergents, it can reduce carbon emission by $1.75 \mathrm{mn}$ tonnes in the production process and transportation of detergents, and lower electricity consumption by $8.57 \mathrm{bn} \mathrm{kWh}$. In addition, this can reduce the discharge of wastewater by $2.42 \mathrm{mn}$ tonnes from the consumer-side.

\subsubsection{Leading Textile and Apparel Companies Take the Lead in Energy Conservation and Emission Reduction}

Greenhouse gas emissions during textiles production process are mainly the result of energy consumption, including direct emissions (natural gas, biomass fuel and coal) and indirect emissions (electricity and steam). Fabric production is responsible for most energy consumption. Major waste products include wastewater, exhaust gas and solid waste. Wastewater and exhaust gas are mainly generated in the processes of printing and dyeing.

Shenzhou International, a leading knitwear manufacturer, continues to step up efforts to improve the utilization rate of water and energies in order to lower the adverse impact of production on environment. The introduction of green production process enables products to be eco-friendly.

Pollution discharge: Shenzhou International (Shenzhou) attaches great importance to pollutant control. When selecting suppliers, Shenzhou emphasizes ecofriendliness of raw materials. They continue to improve their production processes to ensure that technologies used are eco-friendly in different production stages. The company adjusts energy mix by using more renewable energy sources. Shenzhou also introduces new eco-friendly equipment to reduce the consumption of resources and discharges of pollutants. All laws and regulations on pollutants discharge are strictly implemented. The company plans to continue make efforts to reduce unit wastewater discharge and waste gas emissions. The company expects its unit wastewater discharge to decline by about $35 \%$ in 2020, compared to 2015 .

Energy consumption: Shenzhou's Ningbo plant has fully switched over to natural gas as its basic fuel, effectively reducing the adverse impact on the environment. The total consumption of natural gas in 2019 was $59 \mathrm{mn} \mathrm{m}^{3}$, an increase of $61.44 \%$ YoY. Total consumption of biomass fuel and coal fell to 174,770tonnes in 2019, which is a decrease of $16.15 \%$ YoY. 


\subsubsection{Recycling}

Recycling needs engagements of residents, governments, and enterprises. In this section, we will mainly discuss the optimization of product packaging and the recycling of express delivery packaging. Optimizing packaging is the first step to promote recycling which requires the engagement of the packaging manufacturers. Regarding the recycling of retired products, we will focus on consumer goods manufacturers such as the home appliances industry where recycling and trade-in programs may reduce carbon emissions. The reusage of delivery packaging also needs to engage all stakeholders.

\subsubsection{Optimizing Packaging is the First Step to Promote Recycling}

Reducing plastic use is the most important measure for carbon emission reduction. According to UCSB, if the plastic output growth slows from $4 \%$ to $2 \%$, carbon emissions from plastic products in 2050 may decline by $56 \% .^{9}$ The biodegradable plastic industry has been growing rapidly in recent years. The use of biodegradable plastics in consumer goods packaging can help lower carbon emissions.

Excessive packaging is another issue that needs to be addressed. Excessive packaging is a long-term problem for the baijiu industry. Due to the rising environmental awareness among enterprises and consumers, convenient packaged baijiu are gradually replacing boxed baijiu, and glass bottles are replacing traditional ceramic bottles. In the past 5 years, sales of convenient packaged baijiu increased at a CAGR of $20 \%$, and we expect this figure to grow at a CAGR of $15 \%$ over the coming 5 years. Compared with ceramic bottles, recycling of glass bottles generates lower carbon emissions, as well. We believe these new trends can help lower carbon emissions from the packaging process.

\subsubsection{Recycling Needs Active Engagement of Manufacturers}

Waste recycling is one of the most direct ways to reduce carbon emissions (Table 9.1). The carbon emissions from the recycling process are usually much lower than those from remanufacturing and landfilling. Studies have shown that depending on types of materials, one tonne of recycled waste can reduce carbon emissions by up to 8.1tonnes. Meanwhile, sorting of plastics can significantly improve efficiency of garbage recycling, which can help reduce unit carbon emissions by $50 \%-100 \% .{ }^{10}$

The replacement of home appliances can help improve energy efficiency of existing ones. Used home appliances contain nonferrous metals, rubber, and toxic

\footnotetext{
${ }^{9}$ Strategies to Reduce the Global Carbon Footprint of Plastics, Zheng et al. Nature Climate Change 9, 374-378(2019).

${ }^{10}$ Greenhouse Gas Emission Factors for Recycling of Source-segregated Waste Materials. D.A. Turner et al. / Resources, Conservation and Recycling 105 (2015) 186-197.
} 
Table 9.1 Contribution of waste recycling to carbon emission reduction

\begin{tabular}{l|c}
\hline Waste material type & Net $\mathrm{CO}_{2}$ Eq. per tonne $(\mathrm{kg})$ \\
\hline Glass & 314 \\
\hline Paper & 459 \\
\hline Card & 120 \\
\hline Books & 117 \\
\hline Steel cans & 862 \\
\hline Aluminium cans & 8,143 \\
\hline Scrap metal & 3,577 \\
\hline Mixed plastics & 1,024 \\
\hline Mixed plastic bottles & 1,084 \\
\hline PET & 2,192 \\
\hline PVC & 1,549 \\
\hline Wood & 444 \\
\hline Light bulbs & 779 \\
\hline Fridge and freezers & 853 \\
\hline Automotive batteries & 435 \\
\hline Vegetable oil & 2,759 \\
\hline Composite food & 452 \\
\hline Textiles and footwear & 3,376 \\
\hline Sece
\end{tabular}

Source Greenhouse Gas Emission Factors for Recycling of Sourcesegregated Waste Materials. D.A. Turner et al. Resources, Conservation and Recycling 105 (2015) 186-197, CICC Research

substances such as lead and mercury and they may generate a large number of pollutants without proper handling. We estimate that refrigerators, washing machines, air conditioners, and color TVs with a service life of more than 9 years accounted for $11 \%, 21 \%, 9 \%$, and $20 \%$ of their respective total ownerships in China, implying a total of around $330 \mathrm{mn}$ units. So the replacement of home appliances needs active engagement from enterprises and appropriate policies from governments.

Soft drink companies are actively involved in recycling, which may improve the recycling efficiency of PET bottles and reduce carbon emissions. China has a huge demand for soft drink bottles. Given its high economic benefits, recycling of soft drink bottles is already well-established. China's soft drink industry mainly uses disposable PET packaging. According to China Chemical Fiber Website, total demand for PET bottles from China's soft drink industry maintained steady growth in 2017-2019, reaching 4.29mn tonnes in 2019 (Fig. 9.10). Thanks to the wide adoption of recycled bottles, high economic benefits, and sound recycling system, China's recycling rate of PET bottles exceeded 94\% in 2019 (a high figure compared by international standards, according to the China Beverage Industry Association, Table 9.2). However, China's recycling market still has significant potential in its recycling technology and efficiency. 
Fig. 9.10 Demand for PET bottles from China's soft drink industry and YoY growth in 2017-2019. Source ccf.com.cn, IPO prospectus of CR Chemical Materials, CICC Research

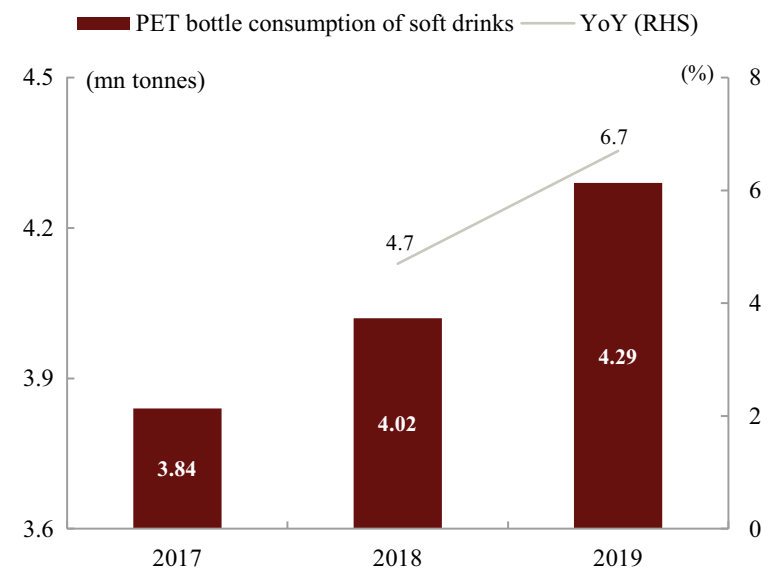

Table 9.2 Recycling rates of PET drink packages by country and region in 2019

\begin{tabular}{l|l|l}
\hline Country & Package types & Recycling rate (\%) \\
\hline China & PET bottle & $>94$ \\
\hline Germany & $\begin{array}{l}\text { Can, PET bottle, } \\
\text { glass bottle }\end{array}$ & 97 \\
\hline $\begin{array}{l}\text { The Czech } \\
\text { Republic }\end{array}$ & $\begin{array}{l}\text { Beer and soft } \\
\text { drinks bottle }\end{array}$ & 99 \\
\hline Finland & $\begin{array}{l}\text { Can, PET bottle, } \\
\text { glass bottle }\end{array}$ & 93 \\
\hline $\begin{array}{l}\text { US (varies among } \\
\text { states) }\end{array}$ & $\begin{array}{l}\text { Beer and soft } \\
\text { drinks bottle }\end{array}$ & $50-85$ \\
\hline Norway & PET bottle & 95 \\
\hline Denmark & $\begin{array}{l}\text { Can, PET bottle, } \\
\text { glass bottle }\end{array}$ & 89 \\
\hline Sweden & Can, PET bottle & 84,81 \\
\cline { 2 - 3 } & Glass bottle & 93 \\
\hline Belgium & PET bottle & $>85$ \\
\hline Japan & PET bottle & 92 \\
\hline Switzerland & PET bottle & 82 \\
\hline
\end{tabular}

Source China Beverage Industry Association, Chinese Research Academy of Environmental Sciences, The Council for PET Bottle Recycling of Japan, CICC Research

Nongfu Spring plans to collect and recycle 1mn 19L packaging bottles each year. These bottles will be remanufactured into plastic products. In addition, international soft drink giants have begun to focus on carbon reduction actions in recent years by using more recycled PET to manufacture beverage packaging. 
The packaging of rice, flour and oil mainly made with PET plastic bottles and plastic woven bags in China. The current recycling rate for those packaging is low. According to Recycling Plastics Branch of China National Recycling Resources Association, China Packaging Federation, and Euromonitor, the recycling rate of PET plastic bottles for cooking oil in 2019 was about $83 \%$ in China, compared to $85 \%$ in Europe and $93 \%$ in Japan. The recycling rate of plastic woven bags for rice and flour in 2019 was about $24 \%$ in China, compared to $42 \%$ in Europe and $47 \%$ in Japan. There are many reasons behind the low recycling rate of plastic woven bags for rice and flour, including difficulty in sorting, high recycling cost and inefficient recycling system. The active engagement of enterprises may help increase the recycling rate.

\subsubsection{Reusing of Express Delivery Packaging}

Although package delivery service is gradually more convenient than before, delivery packaging has brought several challenges to urban cleaning and environmental protection, including the low recycling rate of delivery packaging (less than 20\%), redundant packaging and the low utilization rate of degradable garbage. Targeted measures such as "3R1D" were adopted to reduce the utilization of express packaging. The three Rs are the abbreviations of "Reduce", "Reuse" and "Recycle", while the " $\mathrm{D}$ " is the abbreviation of "degradable".

Reduce: The volume and weight of packaging materials should be minimized in order to lower resource consumption. For example, reducing the redundant packaging of e-commerce parcels (zero secondary packaging by 2025) and increasing the filling rate of packages through smart packaging algorithm.

Reuse: Packaging materials should be reused to the maximum level in order to reduce the consumption of disposable materials. According to China's State Post Bureau (SPB), 2mn recyclable shipping boxes were put into use and utilization rate of recyclable transit bags reached $75 \%$ in 2019 . The SPB estimated that the scale of recyclable express delivery parcels will reach 10mn by 2025 .

Recycle: The wasted express delivery packaging materials can be recycled into new packaging materials through reproduction. For example recycled corrugated paper can be recycled into produce pulp.

Degradable: Degradable plastics can be used to replace disposable plastics. The most popular degradable materials are plant-based plastics and Polylactic acid.

\subsubsection{Sharing Economy}

With the emergence of the sharing economy as a hot topic for startups over the past two or three years, many new business models have emerged. While the umbrella sharing and toy sharing systems have disappeared and the popular bicycle sharing system is waning, the once-obscure power bank-sharing is beginning to dominate the Chinese market. The sharing economy epitomizes a lifestyle philosophy that values 
renting and sharing. As the sharing economy matches productivity with consumption demand more efficiently, it can save resources and support a low-carbon economy.

The power bank sharing system has reduced Chinese consumers' purchase of power banks, thus reducing the carbon emissions caused by power bank productions. According to China Internet Network Information Center (CNNIC), China has $932 \mathrm{mn}$ mobile internet users. Without the power bank sharing system, assuming every mobile internet user owns one power bank and the average replacement cycle is three years, we estimate that the annual demand for power banks may reach $300 \mathrm{mn}$. According to iResearch's statistics, in 2019, the number of the shared power bank users was nearly $250 \mathrm{mn}$ and the transaction amount reached about Rmb8bn. This means that users spend Rmb32 on shared power banks on average. As each user spends Rmb1-1.5 each time they use shared power bank, it is estimated that they use shared power banks 20-30 times. On average, shared power banks are rented out 0.8 times per day, indicating that there are $20-30 \mathrm{mn}$ power banks in the market.

In addition to power bank sharing, many other business models of the sharing economy help reduce carbon emissions by more efficiently meeting people's production and living needs. These business models include ride sharing, workspace sharing, and study room sharing.

Different sharing economy business models centralize the originally scattered and individualized needs. This can minimize unnecessary production, improve production efficiency created by the economies of scale, and create a lower-carbon production model that requires larger upfront investment, thus further reducing carbon emission.

For example, WeWork offices are usually located close to metro stations with the purpose of encouraging low-carbon travel. Additionally, WeWork adopted an intelligent booking system for all meeting rooms and remote meetings are encouraged to reduce emissions. And all office supplies should switch to digitalized products or use recyclable materials. In the future, thanks to further exploration of demands for sharing economy, model innovations and technological progressions, we believe that social production methods will become low carbon and energy-saving.

\subsubsection{Environmental, Social, and Governance (ESG) Development}

ESG refers to an investment philosophy and evaluating standards that pay attention to the environmental, social and governance performance of enterprises. It helps evaluate the contribution of an enterprise to sustainable economic growth and social responsibility (Fig. 9.11).

ESG pushes enterprises to pursue not only the maximum self-interest but also maximum social interest. Companies with good ESG performance can better anticipate and manage opportunities and risks from economic condition, environmental problems and social changes for now and in the future. They pay more attention to 
Fig. 9.11 ESG of consumer goods companies. Source CICC Research

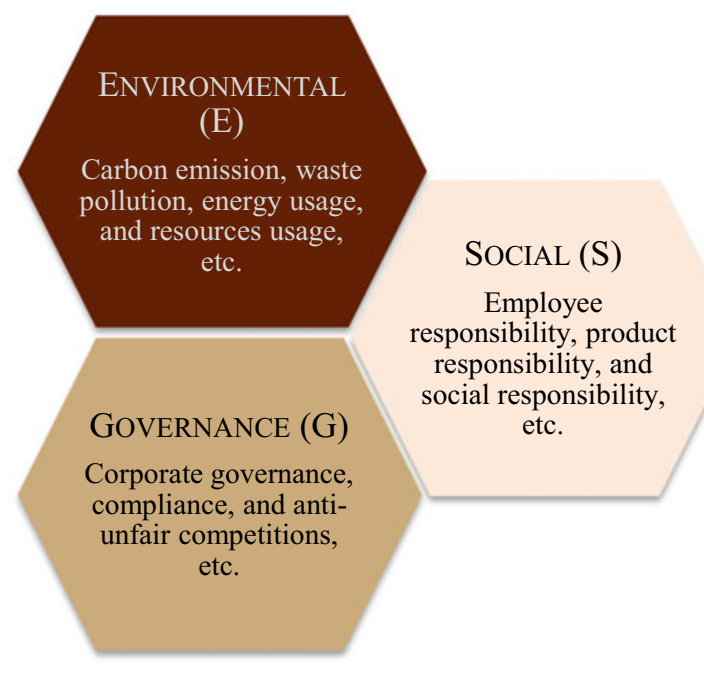

quality, production innovations, environmental protections, energy saving and carbon emission reductions. These can lower operating costs, create competitive advantages and generate long-term values. China's leading home appliance companies have made substantial progress in the fields of energy-saving, emission reduction and waste recycling.

Midea and Haier have won recognition from overseas investors because of their emphasis on ESG performance, which were fully disclosed in their social responsibility reports. Haier's energy consumption per unit of output value in 2017, 2018 , and 2019 dropped by $13.22 \%, 16.67 \%$, and $6.77 \%$ year-on-year(YoY), and carbon dioxide emissions were reduced by 44,221 tonnes and 10,503tonnes in 2018 and 2019. Haier Smart Energy Center uses automation and information technologies with central management model to dynamically monitor and digitally control water, electricity and natural gas consumption in all factories. The center automatically controls energy conversion, transportation, distribution and consumption and accurately collects energy data to predict, analyze and optimize energy consumption. 


\subsection{Policy Formulation and Social Governance: Comparing China with Other Countries to Identify Future Directions}

\subsubsection{Home Appliances: Energy Efficiency Standards, Energy-Saving Subsidies and Recycling Systems Need to Be Improved}

China's current entry-level energy efficiency standards for home appliances are about $20 \%$ lower than those of the US, Europe, and Japan (statistical methods and dimensions not completely comparable). ${ }^{11}$

For air conditioners, refrigerators and washing machines, the US has introduced the mandatory Energy Guide label (under the supervision of Department of Energy) and the voluntary ENERGY STAR label (under the supervision of Environmental Protection Agency).

The European Union Directive (EU) No. 626/2011 requires that air conditioners with a rated cooling capacity equal or greater than $12 \mathrm{~kW}$ must be affixed with an energy efficiency label. This energy efficiency label is required to indicate the annual power consumption. The EU has also enacted similar regulations on refrigerators and washing machines. ${ }^{12}$

Japan's energy efficiency standards for household appliances mainly include the quasi-mandatory Top Runner Program, mandatory energy-saving labels for electrical appliance retailers, and voluntary energy-saving labels.

Having analyzed energy efficiency standards for air conditioners and refrigerators in Japan and the US, we find that the minimum energy efficiency standards for home appliances in developed countries are about 10\%-30\% higher than that of China (statistical methods and dimensions not completely comparable).

Subsidies can help promote energy-efficient home appliances. Between 2009 and 2013, China's household air conditioner industry experienced two rounds of subsidies for energy-efficient products and two rounds of energy efficiency standards upgrades. Historical experiences indicate that these subsidies can help manufacturers and consumers switch to energy-efficient products smoothly. On 10 February 2021, the Ministry of Commerce called for expanding the sales of energy-efficient home appliances and green products. We believe that moderate energy-saving subsidies can enhance the competitiveness of energy-efficient products, thereby improving the

\footnotetext{
${ }^{11}$ China, US and Japan have different classifying standards. Some of the measurements used in these classifying standards are not comparable. For example, air conditioner classifying standards in China use APF measurement while the US uses EER measurement. These two measurements are not comparable.

12 The Commission Directive 94/2/EC of 21 January 1994 implementing Council Directive 92/75/EEC with regard to energy labelling of household electric refrigerators, freezers and their combinations; Delegated regulation 2010/1061 - Supplement to Directive 2010/30/EU with regard to energy labelling of household washing machines Text with EEA relevance.
} 
energy efficiency structure of home appliances, and helping China achieve carbon neutrality as soon as possible.

In addition, numerous countries have developed carbon footprint assessment standards to encourage the production and consumption of low-carbon products, and quantify the greenhouse gas emissions of products by "carbon labels". For example, the international standard ISO/TS14067 and the British Standards Institution's PAS2050 are two widely-used carbon footprint accounting and certification standards. "Carbon label" is a voluntary certification index, which can help companies establish a positive corporate image of low carbon and environmental protection, attract more consumers who are concerned about climate change, and enhance competitiveness of products in the international markets that have stricter environmental laws and regulations.

Environmental protection requirements include:

The US federal government has passed the Toxic Substances Control Act (TSCA) and state governments have passed other relevant laws and regulations.

Products in the EU market need to meet the electronic waste recycling requirements listed in the EU's Waste Electrical and Electronic Equipment (WEEE) Directive. For example, the recovery rate of temperature exchange devices, including air conditioners, refrigerators, freezers and others, must reach $85 \%$. And the reuse and recycling rate must reach $80 \%$. The products also need to comply with the hazardous substance control requirements in the Restriction of Hazardous Substances (RoHS) Directive and the ecological design requirements in the Energy-related Products (ErP) Directive. In addition, there are voluntary eco-labels, such as the EU Ecolabel that applies to refrigerators, washing machines, dishwashers, and vacuum cleaners, and the Nordic Swan Ecolabel that applies to refrigerators, washing machines, and kitchen appliances.

In Japan, air-conditioners, refrigerators, and washing machines need to meet recycling requirements for waste home appliances in the Home Appliance Recycling Law. Air-conditioners, refrigerators, washing machines, dryers and microwave ovens also need to meet the hazardous substance control requirements stipulated by J-MOSS.

While establishing environmental protection standards, China also continues to improve its used home appliance recycling system:

In 2012, China introduced the Administrative Measures for the Collection and Use of Waste Electrical and Electronic Product Disposal Fund, establishing a fund to subsidize companies that dismantle and dispose of used home appliances. However, the fund has a large funding gap due to insufficient budgets and cannot meet actual needs.

In May 2020, China introduced the Implementation Plan on Improving the Waste Home Appliance Recycling and Disposal System to Promote Home Appliance Replacement Consumption, encouraging home appliance manufacturers to develop self-owned recycling networks, commissioned recycling, joint recycling, and new internet-based recycling models, as well as to launch trade-in programs.

In December 2020, China issued the Action Plan on Actively Building a Waste Home Appliance Recycling and Disposal Industry Chain to Promote Home Appliance Replacement Consumption. 


\subsubsection{Furniture: Promote Sustainable Use of Forest Resources}

The EU and the US imposed strict supervisions over logging and the production of wooden products, and promulgate relevant laws and regulations to promote the sustainable use of forests and avoid excessive logging and timber consumption.

On the global level, the FSC forest certification (FSC stands for Forest Steward Council, a non-profit international organization initiated by the World Wide Fund for Nature) aims to ensure a sustainable operation of the forestry production industry chain and encourage the public to purchase standardized forest products to improve forest management, promote sustainable use of forests and avoid excessive logging and consumption.

The EU and the US have also issued corresponding laws and regulations. For example, both Lacey Act Amendment and the European Union Timber Regulation require relevant documents to prove the legality of the source of timber, and impose severe punishments on illegal trading of wooden products.

\subsubsection{Packaging: Overseas Experience and the Overcoming of Difficulties}

\subsubsection{Product Packaging: Comprehensive Regulation is Imperative}

China has issued multiple documents to regulate product packaging. In 2014, the General Administration of Quality Supervision, Inspection and Quarantine and the Standardization Administration issued the General Rules for Restricting Excessive Packaging of Goods, promulgating requirements on packaging costs, materials, and design. Many local governments have followed suit.

In recent years, the central and local governments, food delivery platforms and catering companies have adopted plastic reduction measures to support sustainable development.

In terms of the use of plastic packaging, the National Development and Reform Commission (NDRC) and the Ministry of Ecology and Environment (MEE) issued the Opinions on Further Strengthening the Control of Plastic Pollution in 2020. According to the document, the use of non-degradable plastic bags shall be prohibited by the end of 2020 in shopping malls, supermarkets, pharmacies, bookstores, as well as food delivery services and exhibition activities in urban areas of municipalities, provincial capital cities, and cities under separate state planning. Additionally, the consumption intensity of non-degradable disposable plastic tableware in the food delivery industry should be reduced by $30 \%$ by 2025 in cities above the prefecture level. In terms of plastic packaging recycling, Xiamen introduced new rules for garbage classification in July 2020, reclassifying disposable plastic lunch boxes, 
plastic bags from "other garbage" into "low-value recyclables" and including them in the recycling system.

Globally, plastic restriction policies are becoming stricter. With the rise of global awareness of environmental protection and emission reduction, developed economies such as the EU and the US are continuously tightening their regulations over plastic packaging products and restricting the use of plastic packaging. The Chinese authorities can improve existing systems and regulations based on international experience. For example, the EU has banned the production and sale of disposable tableware and other disposable plastic products from 2021, and replaced them with paper, straw, or reusable hard plastics. The UK announced in 2019 that it would introduce a tax on various plastic products. Japan has a higher recycling rate of PET bottles and rice/flour plastic woven bags than China, which helps the country reduce carbon emissions (Fig. 9.12). We attribute this to Japan's strict regulations, comprehensive and meticulous recycling system, and mature technologies.

Strict regulations lay the foundation for packaging recycling. Japan has formulated a number of regulations on packaging recycling. The country promulgated the Waste Management and Public Cleansing Law in 1970 and the Container and Packaging Recycling Law in 1995, and established a "Reduce, Reuse, Recycle" policy framework, stipulating that PET bottle manufacturers and food manufacturers using PET bottles need to bear the cost of recycling.

Japan's comprehensive and meticulous recycling system becomes a formidable force. A recycling system for plastic products in Japan has been in place for decades.

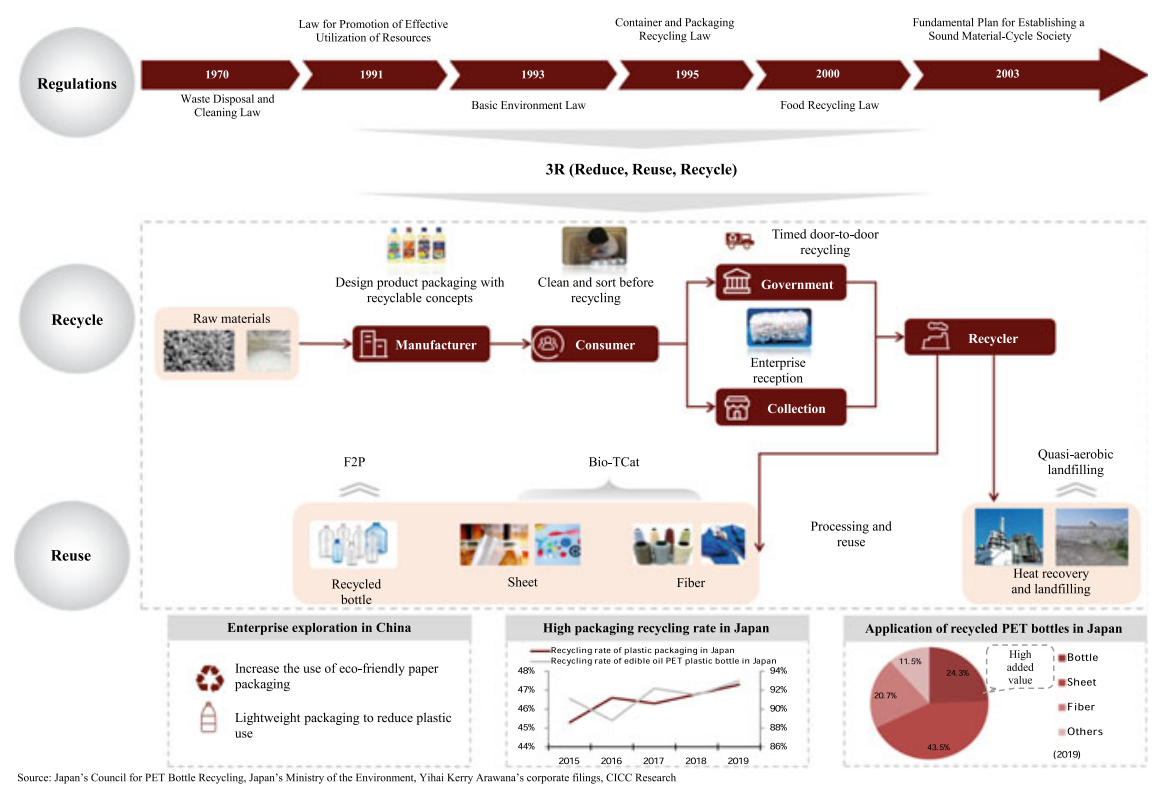

Fig. 9.12 Japan's recycling experience. Source Japan's Council for PET Bottle Recycling, Japan's Ministry of the Environment, Yihai Kerry Arawana's corporate filings, CICC Research 
Waste plastic packaging is cleaned in advance by residents. It is sorted and recycled by government-designated personnel or recycled through various collection points. Then recycling companies carry out heat recovery, landfill treatment, processing and reuse.

Mature reusable technologies can help. Japan's waste plastic reuse technologies mainly include mechanical treatment and chemical degradation. $24 \%$ of the recycled plastic waste is used to produce high value-added bottles. Japan uses F2P and BioTcat technologies to keep chemically degraded molecules tough and safe for food, thereby realizing the reuse of plastic waste.

The deposit refund system in Germany is a model of efficient recycling of PET bottles. At present, the mainstream international method for recycling of PET bottles is the deposit refund system, which has been adopted by Western European countries, Canada, and some states in the US. Germany's deposit refund system was approved by legislature in 1991 and implemented in 2003, mainly for various beverage packaging, such as PET bottles, aluminum packaging, and glass. We believe Germany's recycling system possesses the following advantages:

Clear rights and responsibilities: The system lays out the responsibilities of manufacturers, retailers, and consumers to contribute to the circular economy.

Digital supervision and management: The operator established by the retail and manufacturing industry associations supervises and maintains the system and monitors the overall process digitally.

High level of automation: In the recycling system, $80 \%$ adopts automatic recycling and $20 \%$ adopts manual recycling.

Large-scale reuse: Their reprocessing process achieves economies of scale.

As one of the first countries to establish a deposit refund system, Germany has achieved a high PET recycling rate by virtue of this system, and has increased the proportion of PET bottles made from recycled materials leveraging an efficient reuse system (Fig. 9.13). According to GVM, the recycling rate of PET bottles in Germany was $97 \%$ in 2015, the utilization rate was $93.5 \%$, and about $34 \%$ of the recycled bottles were reprocessed into PET bottles, much higher than the world average (less than $10 \%)$.

\subsubsection{Delivery Packaging: Difficulties and Breakthroughs}

China has been steadily promoting green delivery packaging, and has issued the Interim Regulations on Express Delivery and the Opinions on Accelerating the Green Transformation of Express Delivery Packaging. However, we still see obstacles in the industry's green transformation.

There are standards for packaging reduction but it is difficult to implement. In 2018, the General Administration of Quality Supervision, Inspection and Quarantine and the Standardization Administration issued national standards for delivery packaging supplies, putting forward requirements for reduction of delivery packaging. However, the porosity and volume ratio in the standards are difficult to determine 


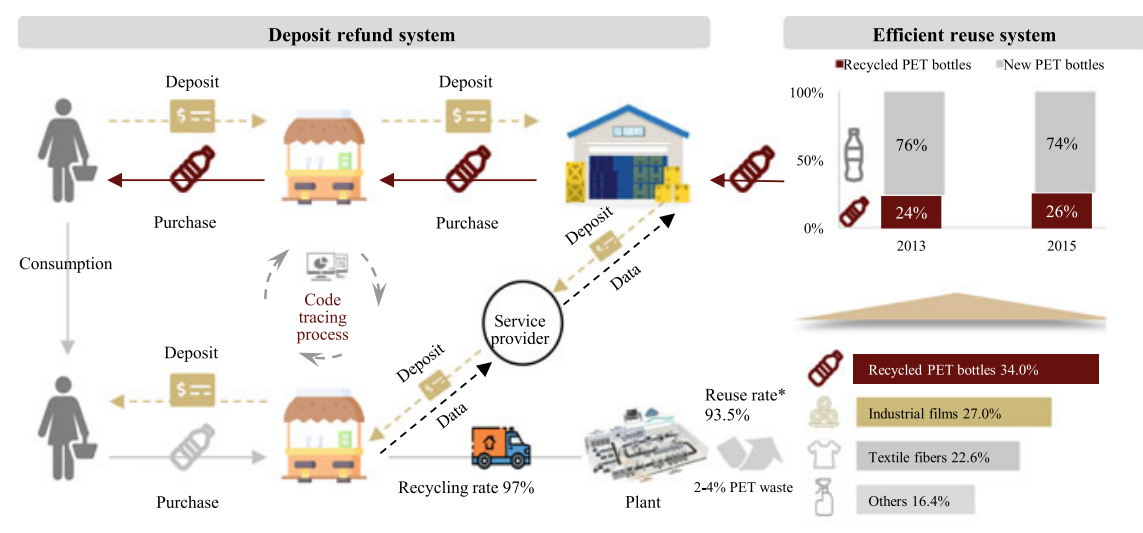

Fig. 9.13 Germany's deposit refund system for recycling of PET bottles and its efficient reuse system. Note All are 2015 data. $* 93.5 \%$ refers to the PET utilization rate after removing the caps and labels. Source CM Consulting, GVM, Forum PET, CICC Research

with the naked eye, while random inspection of delivery companies would be too inefficient.

Recycling requires the cooperation of the government, manufacturers, logistics companies, and the public. In China, there is currently no systematic recycling path. Elderlies, cleaning staff and scavengers remain the main force of recycling. Package delivery companies have gradually initiated recycling actions in recent years, but the overall recycling efficiency is not high. The establishment of a largescale recycling system needs to adopt a multi-pronged approach and refer to the experiences of Germany and Japan.

Both Germany and Japan have enacted relevant laws. Germany introduced the packaging waste management measures and the packaging recycling law, setting recycling targets and time limits for different packaging waste. Japan enacted the energy protection and recycling promotion law and the packaging recycling law to build a recycling system. People's awareness of waste classification is the foundation of the recycling system of these two countries. Both countries have implemented strict household waste classification mechanisms.

Both countries make clear the recyclers and responsible parties. Germany requires packaging material manufacturers to register with the Green Dot, the country's dual system of waste collection, and pay Green Dot fees. Japan has built a large number of recycling sites to make recycling convenient, and encourages residents to participate in collective recycling.

We suggest that China establishes an express delivery packaging recycling system by taking the following actions:

Strengthening laws and regulations on packaging waste management. There are only a few general rules for waste disposal, which only result in relatively minor penalties. 
Raising the public's awareness of recycling: China should promote the idea of packaging recycling through media communication, corporate activities and other methods. It should also implement waste classification in major cities in an appropriate time.

Improving the recycling system: China should make clear the main recycling channels such as campus, community and office. It should also enrich recycling channels such as convenience stores, express delivery outlets and community property management firms, as well as deploy recycling infrastructures such as recycling bins and express delivery cabinets.

\subsubsection{Catering: Promote "Clear Your Plate" Campaign and Organic Food Waste Reusing}

In recent years, China has strengthened anti-food waste education and propaganda, and catering companies have taken measures to help reduce food waste. At present, China mainly relies on education and publicity to reduce food waste. The CPC Central Committee and the State Council issued the Regulations for Party and Government Agencies to Practice Economy and Oppose Waste in November 2013, promoted the "Clear Your Plate" campaign through posters and TV screens or advertising screens? and encouraged ordering and cooking food on demand. The central government's call against food waste received positive responses from consumers and catering companies. In 2013, the official reception and catering expenditures of central government agencies fell $60 \%$ and kitchen waste declined more than $30 \%$.

Looking forward, we believe legal control and technological innovation will help reduce the environmental impact caused by food waste. Foreign countries control food waste mainly through policies, laws and recycling, in an combination with education and publicity. In terms of policies and laws, France introduced the antifood waste law in 2016, stipulating that supermarket donating food that is about to expire will receive a tax credit equal to $60 \%$ of the value of the donated food, and restaurants destroying edible unsold food will face fines of up to $0.1 \%$ of the revenue in the previous fiscal year. In terms of recycling, kitchen waste is used for composting and fermentation in countries such as the UK, the US, and Japan. For example, US company Re-Nuble converts organic waste such as kitchen waste into organic fertilizers, and develops soilless cultivation techniques to grow new crops. Another US company Ecovative Design uses plant fibers from wasted mushrooms and other discarded organic crops to manufacture strong, easily degradable packaging materials. 


\subsection{Quantitative Calculations: A Green Lifestyle Is of Great Significance}

In order to better understand the positive impacts of residents' green lifestyles and consumption habits, companies' active participation, and the government's guidance and promotion on carbon neutrality, we made feasibility assumptions and quantitative calculations on carbon emission reduction that can be achieved by five typical measures: Electricity saving, "Clear Your Plate" campaign, low-carbon diet, delivery packaging recycling, and shared power bank. The results from this model show that the promotion of green lifestyles is of great significance to carbon neutrality.

\subsubsection{Electricity Saving and Use of Clean Energy}

The growth of carbon emissions from household power consumption can be effectively controlled by promoting the improvement in energy efficiency of home appliances and the increase in the proportion of clean energy compared with the baseline situation (where energy efficiency of home appliances and the proportion of clean energy stay the same). With the improvement in energy efficiency of home appliances and the increase in the proportion of clean energy, carbon emissions from household power consumption in 2030 will be $810 \mathrm{mn}$ tonnes, a decrease of $494 \mathrm{mn}$ tonnes compared to the baseline situation, with the former accounting for $57 \%$ of the emission reduction and the latter for $43 \%$. And with the improvement in energy efficiency of home appliances, household power consumption in 2030 will be reduced by $21 \%$ compared to the baseline situation.

To reverse the upward trend of carbon emissions from household power consumption, the rate of increase in the proportion of clean energy needs to be further accelerated. We currently assume that the proportion of clean energy will increase from $34 \%$ in 2020 to $46 \%$ in 2030 .

With the improvement in energy efficiency of home appliances, we estimate that household power consumption will grow at a 3.3\% CAGR over 2020-2030, $2.5 \mathrm{ppt}$ slower than the baseline situation; household power consumption in 2030 will be 1,513.8bn $\mathrm{kWh}, 21 \%$ lower than the baseline situation.

\subsubsection{Reduction in Food Waste}

According to the 2018 China Urban Catering Food Waste Report issued by the World Wide Fund for Nature (WWF) and the Institute of Geographic Sciences and Natural Resources Research, CAS, the amount of food waste in China's urban catering industry reached $17-18 \mathrm{mn}$ tonnes in 2015. 
We assume that: (1) If no measures are taken to reduce food waste, the amount of food waste in urban catering will grow at a 10\% CAGR over 2016-2030, largely the same as the growth rate of urban catering consumption. (2) The structure of food waste in urban catering in the future is consistent with the data in the 2018 China Urban Catering Food Waste Report. (3) For carbon emissions of major foods, we refer to A Comparative Study on Carbon Footprints between Plant-and Animal-based Foods in China.

With the promotion of reduction in urban food waste, we assume that the waste will be reduced by half by 2030 , and we estimate that corresponding carbon emissions will be reduced by $26.91 \mathrm{mn}$ tonnes.

\subsubsection{Changes in Dietary Structure}

We assume that: (1) $10 \%$ of the population will switch from omnivorous diets to ovo-lacto-vegetarian diets, with reference to Environmental Impact of Omnivorous, Ovo-lacto-vegetarian, and Vegan Diet. (2) The remainder of the population will use pork and chicken to replace half of their beef and mutton intake. (3) The remaining food intake structure will remain unchanged. (4) According to the forecast using data from the Food and Agriculture Organization of the United Nations in 2018, Chinese population will reach 1.464 bn in 2030. (5) For carbon emissions of major foods, we refer to A Comparative Study on Carbon Footprints between Plant-and Animal-based Foods in China.

If the Chinese dietary structure in 2030 changes align with our assumptions, we estimate that corresponding carbon emissions in 2030 will be reduced by $66.21 \mathrm{mn}$ tonnes.

\subsubsection{Recycling of Express Delivery Packaging}

Package delivery business volume will continue to grow rapidly in the next few years, and the consumption of packaging material will grow accordingly with package delivery business volume. Parcel volume will reach about 164.4 bn in 2025 , implying a CAGR of $18.3 \%$ over 2018-2025. And the consumption of packaging material will reach $27.46 \mathrm{mn}$ tonnes in 2025 , accounting for $8 \%$ of urban domestic waste collection and transportation volume.

The disposal of delivery packaging through incineration and landfill generates a significant amount of green house gases, especially carbon dioxide, since packaging material is mainly made out of paper or plastic. If the current recycling rate (below 20\%) remains unchanged and reusable delivery boxes are not applied, carbon dioxide generated from the disposal of express delivery packaging (largely landfill and incineration) is expected to increase from 5.27mn tonnes in 2018 to $15.36 \mathrm{mn}$ tonnes in 2025 , a CAGR of $16.5 \%$. 
However, if delivery packaging can be reduced, reused and recycled, we believe corresponding carbon emissions will be reduced significantly.

We assume that by 2025: (1) China's delivery packaging recycling system will improve and the recycling rate will rise to $40 \%$; (2) reduction of redundant packaging and intelligent algorithms will reduce packaging per parcel by $15 \%$; and (3) the number of reusable express delivery boxes will reach more than $10 \mathrm{mn}$. Under these assumptions, carbon dioxide emissions from the disposal of express delivery packaging in 2030 will be reduced from $15.36 \mathrm{mn}$ tonnes by $32.2 \%$ (or about $4.94 \mathrm{mn}$ tonnes) to $10.42 \mathrm{mn}$ tonnes, with the increase in recycling rate contributing $61 \%$ of the emission reduction.

\subsubsection{Shared Power Bank Help Reduce Purchase Demand}

The stock of shared power banks will further expand, as their penetration of major business venues, the number of users, and the times of usage per capita increase. Shared power banks meet the charging needs of users and restrain individuals' purchase demand for power banks. Assuming that there is no breakthrough in charging technology, we estimated the reduction in demand for power banks in the next five years due to the growing use of shared power bank. Considering the reduction in outdoor activities in 2020 due to the pandemic, we make assumptions based on the situation in 2019. Shared power banks are used frequently and their efficiency generally drops significantly after 500 charges assuming that the replacement cycle is 1.5 years.

Shared power bank will reduce the average annual consumption of power banks in the next 10 years by about $100 \mathrm{mn}$ units. Because the specific energy consumption of producing a power bank is not available, we use China's data on carbon dioxide emissions per unit of GDP, i.e. 0.14tonnes per Rmb1,000 of GDP. Assuming that the average price of power banks is Rmb50/unit, shared power banks will reduce the average annual carbon dioxide emissions in the next 10 years by about 700,000 tonnes.

Open Access This chapter is licensed under the terms of the Creative Commons AttributionNonCommercial-NoDerivatives 4.0 International License (http://creativecommons.org/licenses/bync-nd/4.0/), which permits any noncommercial use, sharing, distribution and reproduction in any medium or format, as long as you give appropriate credit to the original author(s) and the source, provide a link to the Creative Commons license and indicate if you modified the licensed material. You do not have permission under this license to share adapted material derived from this chapter or parts of it.

The images or other third party material in this chapter are included in the chapter's Creative Commons license, unless indicated otherwise in a credit line to the material. If material is not included in the chapter's Creative Commons license and your intended use is not permitted by statutory regulation or exceeds the permitted use, you will need to obtain permission directly from the copyright holder.

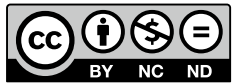

